\section{Ultrasound-guided sclerotherapy for benign non-thyroid cystic mass in the neck}

\author{
Ji-hoon Kim
}

Department of Radiology, Seoul National University Hospital, Seoul National University College of Medicine, Seoul, Korea

Surgical excision has traditionally been the treatment of choice for benign non-thyroid cystic neck masses, including lymphatic malformation, ranula, branchial cleft cyst, thyroglossal duct cyst, and parathyroid cyst. However, there is a tendency toward recurrence after surgery, and surgery may be accompanied by complications, including nerve injuries, vascular injuries, and scar formation. Ultrasound-guided sclerotherapy using various agents has been challenged and successfully applied as an alternative treatment for benign non-thyroid cystic neck masses. This report reviews the available sclerosing agents and describes the applications of sclerotherapy to the treatment of benign cystic masses in the neck.

Keywords: Neck; Cysts; Ultrasonography; Sclerotherapy; Picibanil

\section{Introduction}

For the benign non-thyroid cystic neck masses, including lymphatic malformation, ranula, branchial cleft cyst, thyroglossal duct cyst, parathyroid cyst, and lymphocele, surgery is the first line of treatment. However, complete surgical removal may be difficult, resulting in a tendency toward recurrence, and the potential complications of surgery include muscle weakness, nerve damage, vessel damage, infection, and poor cosmetic outcomes such as scarring and stitch granuloma $[1,2]$. Although ultrasound-guided sclerotherapy for a benign thyroid cyst has been well established, ultrasoundguided sclerotherapy for various non-thyroid cysts has been challenging but has become an accepted alternative treatment, and several authors have advocated sclerotherapy following surgery [2-5]. OK432 (picibanil) and ethanol are the most commonly used sclerosants among the variety of sclerosing agents that are currently available. This article reviews the most common uses of these agents and the indications and outcomes of sclerotherapy for benign cystic diseases of the neck.

\section{Sclerosing Agents}

OK-432 and ethanol are the most widely used sclerosing agents, although numerous sclerosing agents have been used. When necessary, surgical excision after OK-432 treatment has not been considered more difficult.

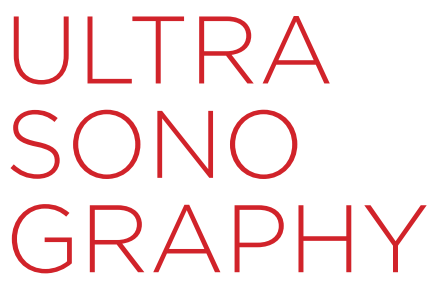

REVIEW ARTICLE

http://dx.doi.org/10.14366/usg.13026 pISSN: 2288-5919 • elSSN: 2288-5943

Ultrasonography 2014;33:83-90

Received: December 28, 2013

Revised: January 27, 2014

Accepted: January 28, 2014

Correspondence to:

Ji-hoon Kim, MD, Department of Radiology, Seoul National University Hospital, Seoul National University College of Medicine, 101 Daehak-ro, Jongno-gu, Seoul 110-744, Korea

Tel. +82-2-2072-3696

Fax. $+82-2-747-7418$

E-mail: jihnkim@gmail.com

\begin{abstract}
This is an Open Access article distributed under the terms of the Creative Commons Attribution NonCommercial License (http://creativecommons.org/ licenses/by-nc/3.0/) which permits unrestricted noncommercial use, distribution, and reproduction in any medium, provided the original work is properly cited.
\end{abstract}

Copyright (C) 2014 Korean Society of Ultrasound in Medicine (KSUM)

How to cite this article:

Kim JH. Ultrasound-guided sclerotherapy for benign non-thyroid cystic mass in the neck. Ultrasonography. 2014 Apr;33(2):83-90. 


\section{OK-432 (Picibanil)}

OK-432 (Chugai Pharmaceutical, Tokyo, Japan) is a lyophilized mixture of a low-virulence strain (Su) of group-A Streptococcus pyogenes incubated with benzylpenicillin $[1,3,6]$. The agent was initially used for chemotherapy in patients with lung cancer or stomach cancer and to reduce malignant pleural effusions or ascites [6]. Since Ogita et al. [7] first reported the treatment of a lymphangioma via an intralesional injection of OK-432 in 1986, OK-432 sclerotherapy has been reported mainly for lymphatic malformations.

OK-432 sclerotherapy is usually performed using one vial (1 Klinische Einheit; KE) of OK-432 mixed in $10 \mathrm{~mL}$ of normal saline, resulting in a $0.01-\mathrm{mg} / \mathrm{mL}$ dilution of $0 K-432$ in a physiological solution $[3,6]$. If the volume of fluid aspirated from the cyst is $<20$ $\mathrm{mL}$, an equal quantity of the diluted OK-432 can be injected directly into the cyst cavity, and irrespective of the amount of fluid aspirated from the cyst, $20 \mathrm{~mL}$ is the maximum recommended volume of OK432. In the case of loculations, the total amount of diluted OK-432 can be divided for injection into each cavity [3].

Although the mechanism of action of OK-432 sclerotherapy is not clearly understood, it is known that the collapse and adhesion of the cystic wall occur after the absorption of the injected OK432 solution. OK-432 causes inflammation of the cyst wall and stimulates the immunocyte secretion of a variety of cytokines, including interleukin-6, tumor-necrosis factor, and interferon gamma, which increases the permeability of the endothelium and induces the apoptosis of the lymphatic endothelium, facilitating the excretion of the lesion into the lymphatic vessels and resulting in a contraction of the cyst. The agent also promotes cyst contraction by activating natural killer cells and recruiting T-lymphocytes $[1,3,8]$.

The skin test for penicillin $\mathrm{G}$ allergy should be performed before OK-432 sclerotherapy [8]. OK-432 sclerotherapy may initially be associated with minor inflammatory responses such as swelling, erythema, pain, and mild fever for up to 5 days in many cases, and it is rarely associated with major side effects such as dyspnea and cellulitis [6]. Kim et al. [1] have reported that 36 of 75 patients experienced minor adverse effects including fever $(n=14)$, odynophagia ( $n=12)$, local pain ( $n=19)$, and/or swelling $(n=10)$ after the treatment of benign neck cysts with OK-432 sclerotherapy. The therapeutic response of OK-432 usually occurs about 6 weeks or more after treatment [6].

\section{Ethanol}

Ethanol is a less expensive and more potent sclerosing agent than OK-432. Its mechanisms of action include rapid dehydration of the cyst wall, protein denaturation that results in clumping of blood cells, and vessel wall necrosis that results in thrombosis and occlusion $[9,10]$. The potential side effects of ethanol sclerotherapy are known to be relatively more severe than those associated with OK-432. Serious complications have included nerve injury, skin necrosis, hemoglobinuria, and severe hypotension. There have been a few case reports of cardiopulmonary collapse, pulmonary hypertension, and death after alcohol embolization, which suggests that acute injection of ethanol may cause serious side effects on the pulmonary circulation $[9,10]$.

Therefore, special care must be taken to avoid leakage during the injection of ethanol. Mason et al. [9] reported the safe dose of ethanol to be $1.0 \mathrm{~mL} / \mathrm{kg}$ (body weight) to prevent complications, including respiratory depression, cardiac arrhythmias, seizures, rhabdomyolysis, and hypoglycemia. Further research aimed at enhancing the safety and efficacy of ethanol sclerotherapy is warranted $[8,9,11]$.

\section{Other Sclerosing Agents}

Bleomycin is an antineoplastic agent that inhibits DNA synthesis and has sclerosing effects on lymphatic malformations. However, the use of bleomycin as a sclerosing agent is problematic because it can cause pulmonary fibrosis $[6,12]$. The tetracycline derivative doxycycline is also an effective sclerosant. However, doxycycline can cause severe discomfort or pain that typically lasts for 1 to 3 hours after injection [6]. Many other agents, including boiling water, quinine, urethane, iodine tincture, nitromin, hypertonic saline, salicylates, cyclophosphamide, sodium morrhuate, sodium tetradecyl sulfate, fibrin glue, Ethibloc, and $50 \%$ dextrose have been used or tried for sclerotherapy $[6,8]$. Fibrin glue is expensive, and Ethibloc may cause an allergic reaction [8].

\section{Indications for Sclerotherapy}

With respect to efficacy, sclerotherapy has been found to have better results in the case of unilocular cysts than in the case of multilocular cysts and has proven more effective for lymphatic malformation than for ranula, branchial cleft cyst, or thyroglossal duct cyst $[1,13]$.

\section{Lymphatic Malformation}

Lymphatic malformation is a congenital malformation of the lymphatic system that consists of cysts of various sizes. It is also called a lymphangioma or a cystic hygroma [6]. The management of lymphatic malformation is challenging. Although surgery is the mainstay of treatment, complete surgical excision may be difficult and is accompanied by the risk of potentially serious complications. Sclerotherapy with various sclerosants has been reported with good results [6,7] (Fig. 1). However, among the macrocystic (loculation volume $\geq 2 \mathrm{~cm}^{3}$ ), microcystic (loculation volume $<2 \mathrm{~cm}^{3}$ ), and mixed 


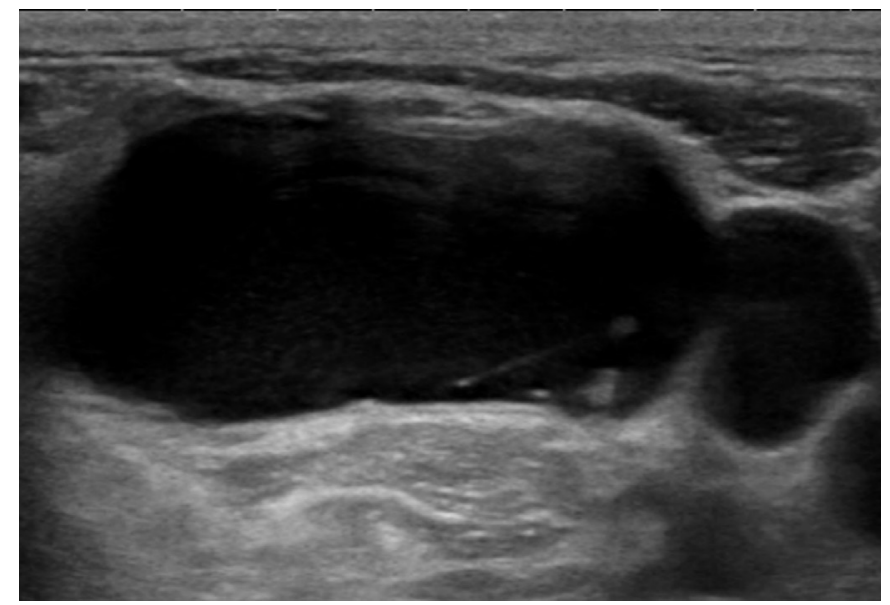

A

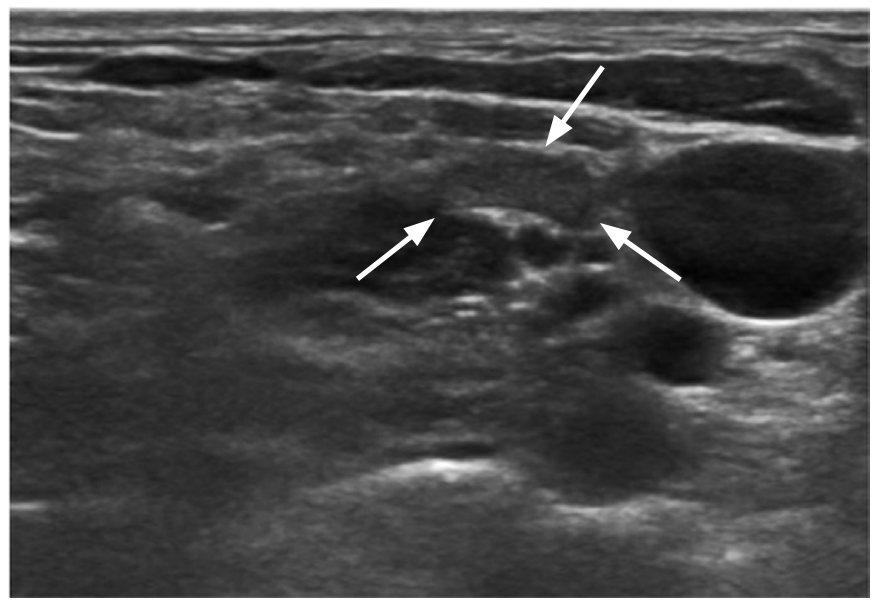

B

Fig. 1. A 54-year-old man with a macrocystic lymphatic malformation treated with ethanol.

A. Ultrasonography reveals a large cystic mass in the right supraclavicular area. B. After treatment with ethanol, the cystic mass decreased markedly, resulting in a small echogenic lesion (arrows).

types, the microcystic and mixed types showed a lower response rate for sclerotherapy than the macrocystic type $[7,12,14]$. For these types, surgery should be considered rather than sclerotherapy [15]. OK-432 has been the most widely reported sclerosing agent in these cases $[12,16]$ and has been reported to be effective in up to $96 \%$ of patients undergoing sclerotherapy for lymphatic malformation in the neck space, with a long-term response rate of $76.3 \%$ [6]. Because the therapeutic response to OK-432 usually takes about 6 weeks or more, and because the number of injections does not correlate with the success rate and surgical excision is not considered to be more difficult after OK-432 sclerotherapy, the exact timing of conversion from sclerotherapy to surgical excision should be chosen carefully [6]. Impellizzeri et al. [8] reported a group of 8 patients who underwent computed tomography (CT)-guided ethanol sclerotherapy for lymphatic malformation. The cysts showed complete disappearance after 1 injection in 7 patients, and there were satisfactory results after 2 injections in 1 patient. There were no significant complications associated with the injection of $98 \%$ sterile ethanol in an amount equivalent to $50 \%$ of the aspirate fluid volume [8].

Puig et al. [17] applied a double-needle procedure to reduce the risk of intralesional pressure elevation and alcohol extravasation in the surrounding tissues in the fluoroscopy-guided sclerotherapy.

Results of sclerotherapy using doxycycline, bleomycin, and Ethibloc for lymphatic malformation have also been published [12], and in a meta-analysis by Adams et al. [18] comparing surgery with sclerotherapy, complications were reported more frequently with surgery, but which treatment is more effective was not clearly established.

\section{Ranula}

A ranula is a pseudocyst or mucocele caused by the leakage of mucus from the sublingual or minor salivary gland. The wall is formed by granulation tissue, connective tissue, or fibrous tissue, and is without epithelium $[19,20]$.

Surgical excision of a ranula along with the sublingual gland has traditionally been the first choice of therapy. However, incomplete excision resulting in eventual recurrence occurs frequently because the ranula is easily ruptured during surgery owing to its thin and friable wall. In addition, there is risk of injury of surrounding vital structures, including the lingual nerve and the submandibular duct $[19,20]$.

Ranulas are classified into intraoral and plunging types. An intraoral ranula is confined to the floor of the mouth and is a slowly enlarging painless fluctuant swelling. In contrast, a plungingtype ranula is a pseudocyst formed by mucus extravasation arising from the sublingual gland located below the mylohyoid muscle; it presents as a swelling in the upper part of the neck. According to Jain et al. [21], all 30 cases of plunging ranula showed either solid echogenic material, fluid material, or both, which suggested the herniation through the defect of mylohyoid muscle from the sublingual space to the submandibular space in their study (Fig. 2).

Because intraoral ranulas have the tendency to rupture after sclerotherapy, the overall outcome of sclerotherapy for a plungingtype ranula is better than that for an intraoral ranula [19]. Rho [19] has reported effective treatment of plunging-type ranulas by injection of a volume of $1 \mathrm{KE}$ OK-432 in $10 \mathrm{~mL}$ of normal saline solution equivalent to the amount of aspirated cyst fluid (Fig. 2). Complete sclerotherapy encompassing the entire plunging tract 


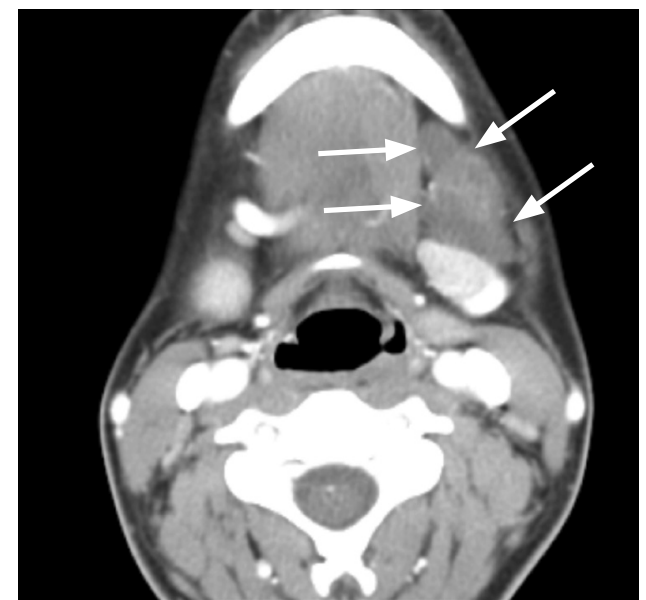

A

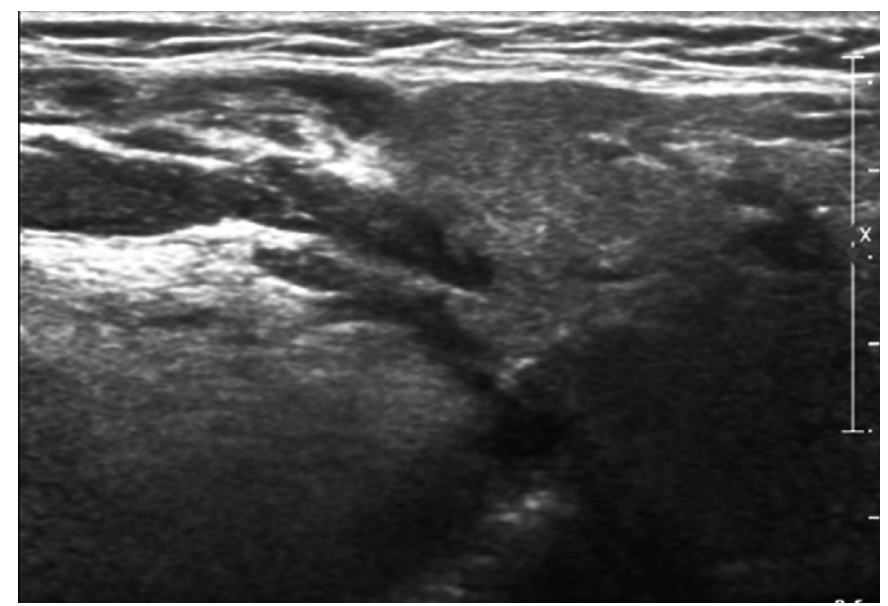

C

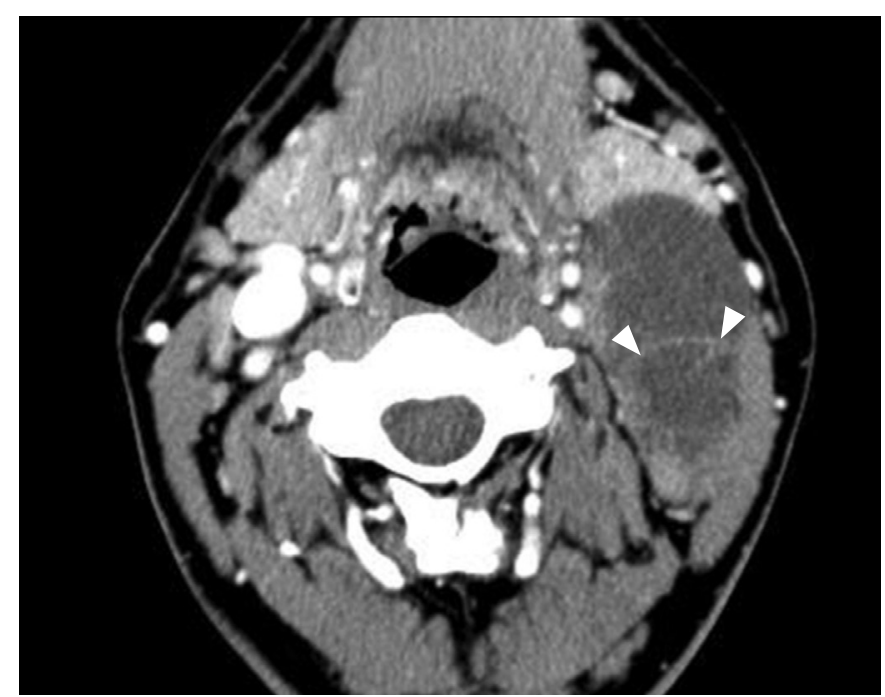

Fig. 3. A 52-year-old woman with a left tonsillar cancer. Computed tomography reveals a cystic mass with septation (arrowheads) in left level II.

B

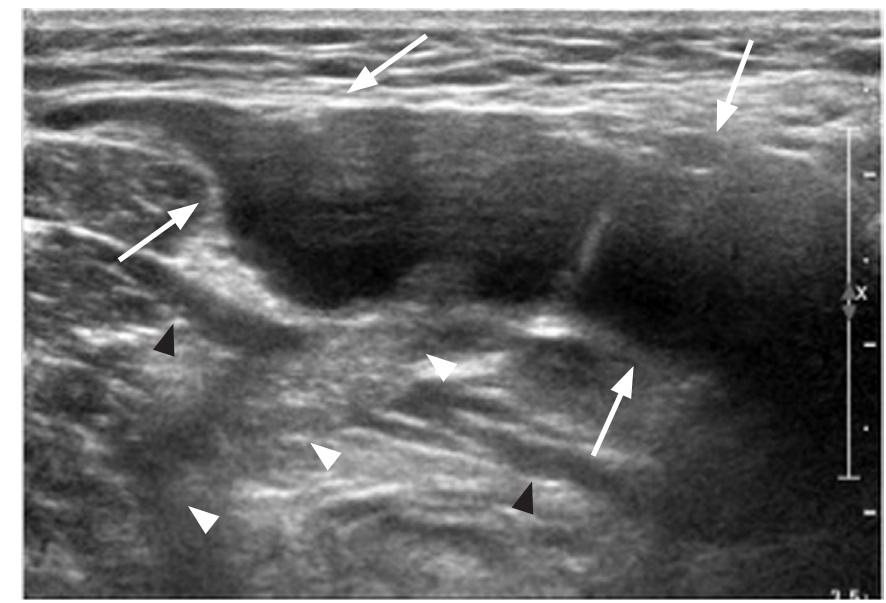

Fig. 2. A 17-year-old girl with a plunging-type ranula treated with OK-432.

A. Computed tomography reveals a lobulated cystic mass in the left submandibular space (arrows). B. Ultrasonography reveals an insinuating septated mass (arrows) that herniates from the sublingual space into the left submandibular space through the mylohyoid muscle (black arrowheads). The herniating tract (white arrowheads) between the sublingual space and the submandibular space is seen as an echogenic tubular structure. C. After three treatments with OK-432, the lesion disappeared completely.

of the plunging-type ranula seems to be important for effective treatment.

\section{Branchial Cleft Cyst}

Although surgery is also a standard treatment for a branchial cleft cyst, Kim et al. [22] have highlighted the potential for the success of the OK-432 treatment by presenting results for 14 of 23 cases of a unilocular branchial cleft cyst that showed complete disappearance after injection of OK-432. Furthermore, in a study by Roh et al. [23], 7 of 12 patients had a complete response to OK-432 injections after 1-3 treatments performed as those described above (i.e., 1 KE OK432 in $10 \mathrm{~mL}$ of normal saline at a volume equivalent to the amount of aspirated cyst fluid). Fukumoto has also reported successful results of ethanol sclerotherapy for the treatment of a branchial cleft cyst [24]. It is important to perform CT to exclude the possibility of branchiogenic carcinoma or other head and neck malignancy before sclerotherapy for branchial cleft cyst. According to Goyal et al. [25], a branchial cleft cyst is frequently large in size and has homogenous 
features; further, malignant cystic adenopathy showed a frequently extracapsular spread and septation (Fig. 3).

\section{Thyroglossal Duct Cyst}

Simple excision methods for thyroglossal duct cysts are associated with high recurrence rates of up to $40 \%-65 \%$. This recurrence rate can be reduced to $2.6 \%-5 \%$ by the Sistrunk procedure. The extended Sistrunk operation, in which the central core of the soft tissue at the anterior neck compartment, from the thyroid gland to the tongue base in addition to the hyoid bone and the fibrous tract, is dissected and removed, has been advocated to prevent recurrence $[26,27]$. The drawbacks of this surgical procedure include the use of general anesthesia, the extent of scarring, and the associated surgical morbidity $[26,27]$.

Up to one-third of the patients present with a concurrent or

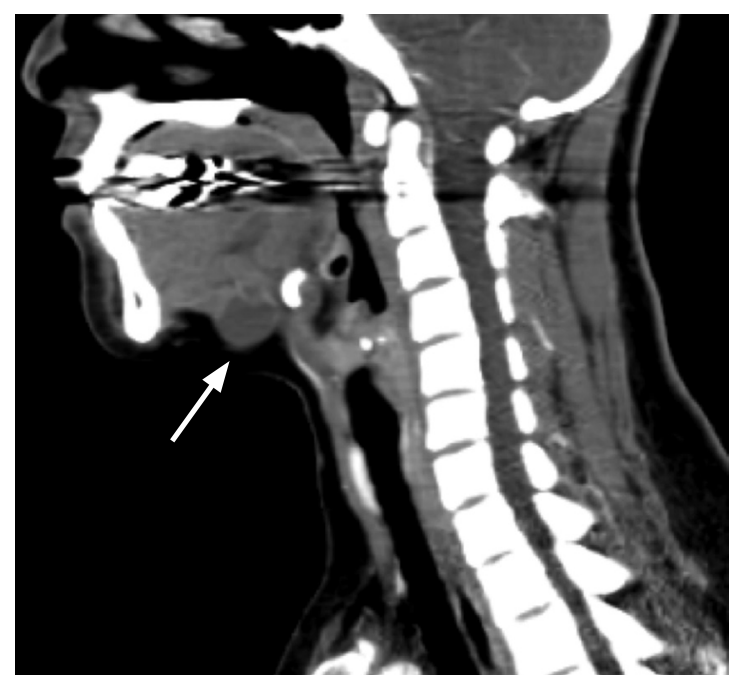

A

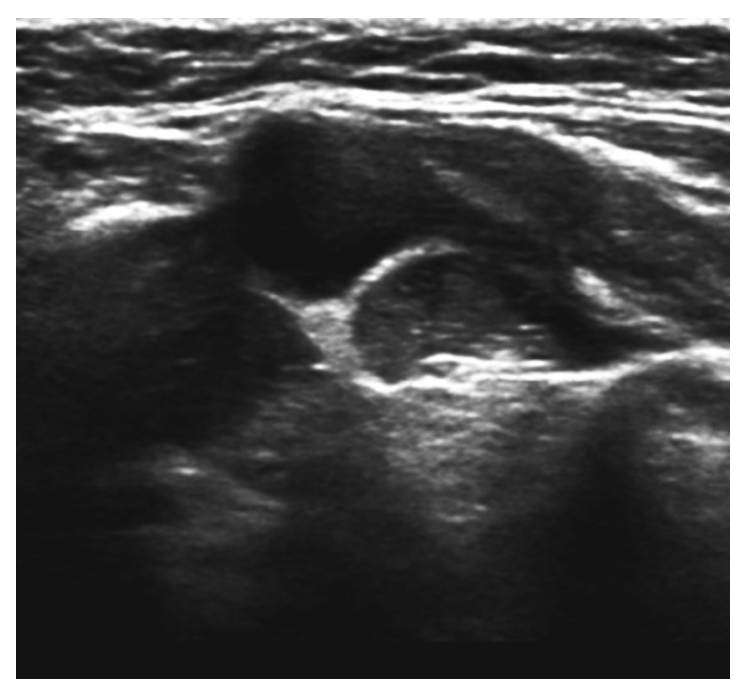

C previous history of infection in the cyst [28]. The presence of inflammation at the time of surgery is an important risk factor for relapse, and the initial treatment should be the administration of antibiotics in the sclerotherapy as well as in the surgery [29]. As a possible alternative, Kim et al. [1] have reported complete regression of a thyroglossal duct cyst after sclerotherapy with 1 KE OK-432 in $10 \mathrm{~mL}$ of normal saline at a volume equivalent to the cyst aspirate in 5 of 11 patients, and although its use is still rare, there have been a few reports of successful ethanol sclerotherapy for these cysts. Further, as described by Kim et al. [27], in one series of 11 patients, there was significant improvement of symptom grade and cosmetic grade along with a mean volume reduction of $81.3 \%$ in thyroglossal duct cysts after ethanol sclerotherapy. In these cases, the treatment consisted of injection of a volume of ethanol equivalent to $50 \%$ $80 \%$ of the aspirate volume, which followed aspiration of as much

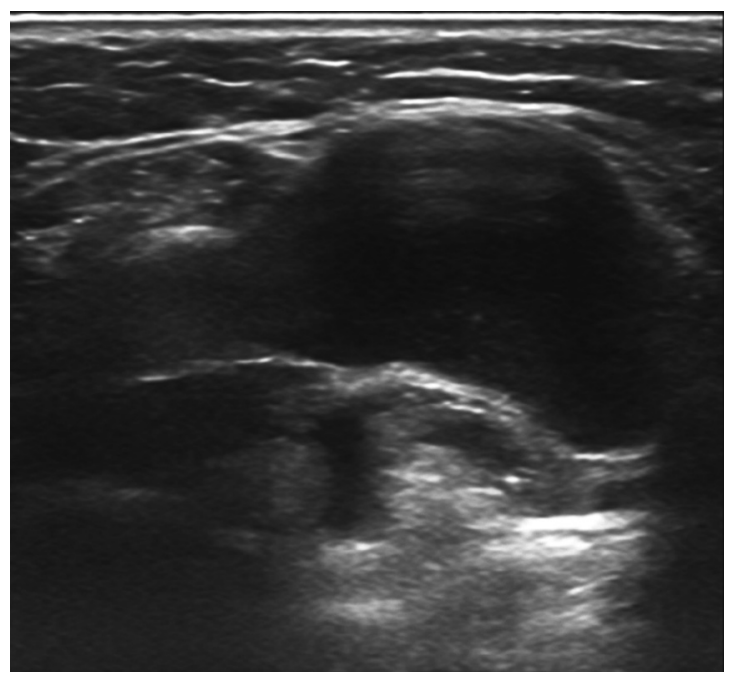

B

Fig. 4. A 30-year-old woman with a thyroglossal duct cyst. A. Computed tomography reveals a cystic mass (arrow) at the anterior and inferior aspects of the hyoid bone. B. Ultrasonography reveals a cystic mass. C. After the treatment with ethanol, the lesion decreased in size. 


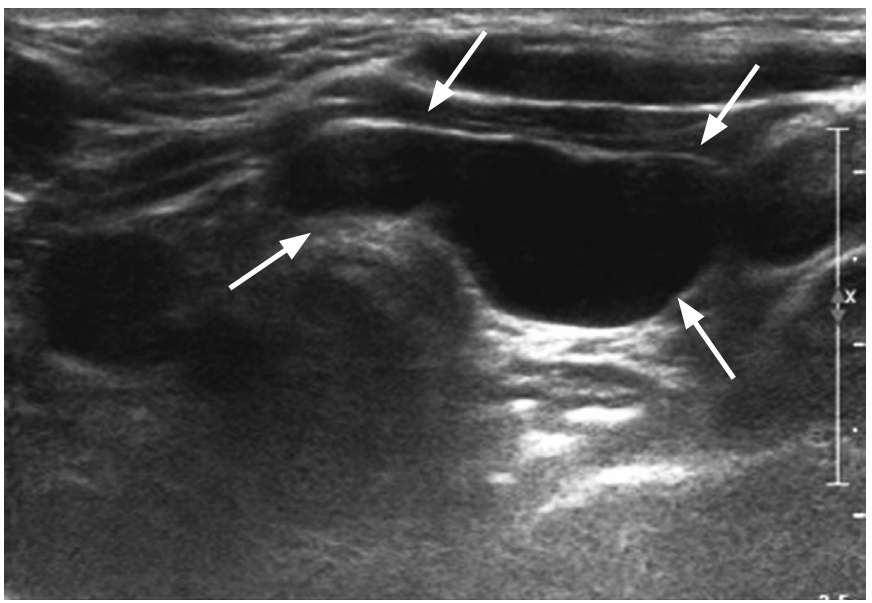

A

Fig. 5. A 63-year-old woman with a parathyroid cyst.

Transverse (A) and sagittal (B) ultrasonography reveals a lobulated pure cystic mass (arrows) in the inferior aspect of the left thyroid gland. After treatment with ethanol, the lesion disappeared completely. fluid as possible $[24,26,27]$ (Fig. 4). In some cases, the authors used a suction pump to facilitate the aspiration of the cyst, because thyroglossal duct cysts often contain a very sticky fluid [27]. They performed needle puncture at the most nondependent portion of the lesion to minimize ethanol leakage [27]. It has been acknowledged that the efficacy of ethanol sclerotherapy for a thyroglossal duct cyst still needs to be validated on a larger scale [27], and as with a branchial cleft cyst, sclerotherapy in the case of a thyroglossal duct cyst must be carefully preformed only after the exclusion of the accompanying thyroid cancer. According to Branstetter et al. [30], CT features suggestive of thyroid duct carcinoma include mural nodules and calcification.

\section{Parathyroid Cyst}

Parathyroid cysts are classified into functional and nonfunctional cysts. Most functional cysts originate from a cystic change of parathyroid adenoma and therefore, exhibit a solid cystic appearance on ultrasonography. Most nonfunctional cysts appear as pure cystic structures on ultrasonography and yield a clear, colorless fluid aspirate [31]. In some cases, differentiation of a parathyroid cyst from a thyroid cyst is difficult and can be achieved by the measurement of the parathyroid hormone in the cystic fluid [31,32]. Sung et al. [31] have successfully treated 4 patients with a nonfunctioning parathyroid cyst by simple aspiration, and in 8 patients who had recurrence of a nonfunctioning parathyroid cyst after simple aspiration, the authors successfully treated the recurrent cysts by injection of an ethanol volume that was $<50 \%$ of the aspirate volume (Fig. 5). In this series, there were no significant complications reported in any of the 12 cases described [31].

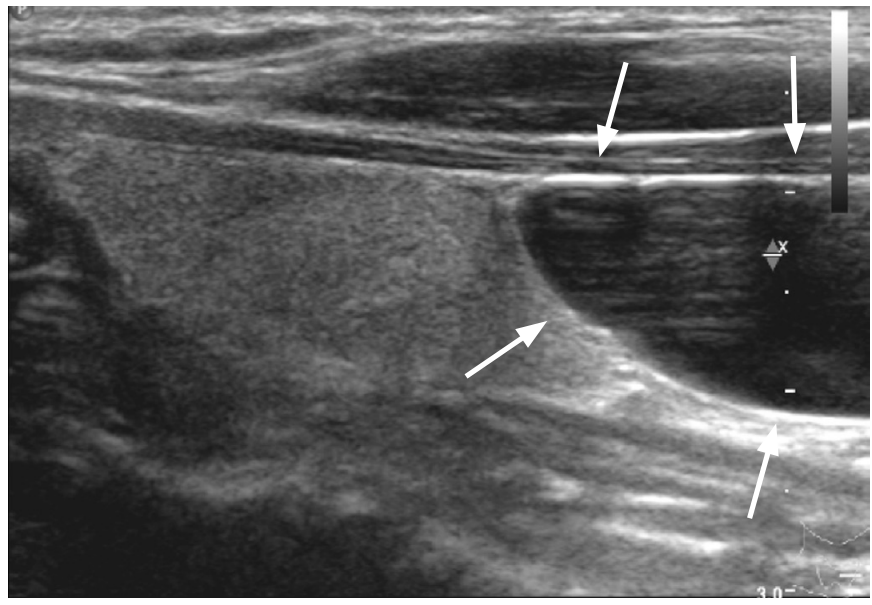

B
Special care must be taken to avoid ethanol leakage during sclerotherapy for these lesions, because most of them are located near the recurrent laryngeal nerve or the tracheoesophageal groove. To minimize leakage of ethanol outside the parathyroid cyst, Sung et al. [31] inserted the needle via the normal thyroid tissue.

\section{Lymphocele}

A lymphocele is a benign cyst, usually unilocular, that may occur spontaneously or after trauma or surgery [33]. Although resection of a lymphocele accompanied by ligation of the involved lymphatic duct is the standard surgical method, there have been a few reports of sclerotherapy using OK-432 or talc as a treatment of these cysts [33-35].

\section{Conclusion}

Sclerotherapy is currently recommended as a less invasive method before surgery for the treatment of a variety of benign non-thyroid cystic masses of the neck. Among the available sclerosants, OK432 has been well-established as a safe and effective agent that has proven useful for the ablation of several different types of cystic masses of the neck. However, OK-432 may be difficult to obtain in a routine clinical setting. In addition, the recurrence rate of cysts and the occurrence of inflammatory reactions after sclerotherapy using OK-432 are not negligible. Therefore, although its side effects are reported to be slightly greater than those of OK-432, ethanol, which is a more potent and more easily accessible sclerosing agent, has been currently used in many hospitals in Korea. Nonetheless, further investigation of the techniques for the safer use of ethanol should 
be pursued, and when the other sclerosing agents are used, the individual characteristics and complications associated with each should be reviewed before sclerotherapy.

ORCID: Ji-hoon Kim: http://orcid.org/0000-0002-6349-6950

\section{Conflict of Interest}

No potential conflict of interest relevant to this article was reported.

\section{References}

1. Kim MG, Kim SG, Lee JH, Eun YG, Yeo SG. The therapeutic effect of OK-432 (picibanil) sclerotherapy for benign neck cysts. Laryngoscope 2008;118:2177-2181.

2. Colbert SD, Seager L, Haider F, Evans BT, Anand R, Brennan PA. Lymphatic malformations of the head and neck-current concepts in management. Br J Oral Maxillofac Surg 2013;51:98-102.

3. Sung MW, Lee DW, Kim DY, Lee SJ, Hwang CH, Park SW, et al. Sclerotherapy with picibanil (OK-432) for congenital lymphatic malformation in the head and neck. Laryngoscope 2001;111:14301433.

4. Roh JL, Kim HS. Primary treatment of pediatric plunging ranula with nonsurgical sclerotherapy using OK-432 (Picibanil). Int J Pediatr Otorhinolaryngol 2008;72:1405-1410.

5. Rho MH, Kim DW, Kwon JS, Lee SW, Sung YS, Song YK, et al. OK432 sclerotherapy of plunging ranula in 21 patients: it can be a substitute for surgery. AJNR Am J Neuroradiol 2006;27:1090-1095.

6. Wiegand S, Eivazi B, Zimmermann AP, Sesterhenn AM, Werner JA. Sclerotherapy of lymphangiomas of the head and neck. Head Neck 2011;33:1649-1655.

7. Ogita S, Tsuto T, Tokiwa K, Takahashi T. Intracystic injection of OK432: a new sclerosing therapy for cystic hygroma in children. $\mathrm{Br} J$ Surg 1987;74:690-691.

8. Impellizzeri P, Romeo C, Borruto FA, Granata F, Scalfari G, De Ponte $F S$, et al. Sclerotherapy for cervical cystic lymphatic malformations in children: our experience with computed tomography-guided $98 \%$ sterile ethanol insertion and a review of the literature. J Pediatr Surg 2010;45:2473-2478.

9. Mason KP, Michna E, Zurakowski D, Koka BV, Burrows PE. Serum ethanol levels in children and adults after ethanol embolization or sclerotherapy for vascular anomalies. Radiology 2000;217:127132.

10. Gelczer RK, Charboneau JW, Hussain S, Brown DL. Complications of percutaneous ethanol ablation. J Ultrasound Med 1998;17:531533.

11. Alomari Al, Karian VE, Lord DJ, Padua HM, Burrows PE. Percutaneous sclerotherapy for lymphatic malformations: a retrospective analysis of patient-evaluated improvement. J Vasc Interv Radiol 2006;17:1639-1648.
12. Renton JP, Smith RJ. Current treatment paradigms in the management of lymphatic malformations. Laryngoscope 2011;121:56-59.

13. Kim CH, Rho MH. OK-432 sclerotherapy for benign cystic head and neck lesions. J Korean Radiol Soc 2003;49:461-467.

14. Ogita S, Tsuto T, Nakamura K, Deguchi E, Iwai N. OK-432 therapy in 64 patients with lymphangioma. J Pediatr Surg 1994;29:784-785.

15. Gilony D, Schwartz M, Shpitzer T, Feinmesser R, Kornreich L, Raveh E. Treatment of lymphatic malformations: a more conservative approach. J Pediatr Surg 2012;47:1837-1842.

16. Balakrishnan K, Menezes MD, Chen BS, Magit AE, Perkins JA. Primary Surgery vs Primary Sclerotherapy for Head and Neck Lymphatic Malformations. JAMA Otolaryngol Head Neck Surg 2014;140:41-45.

17. Puig S, Aref H, Brunelle F. Double-needle sclerotherapy of lymphangiomas and venous angiomas in children: a simple technique to prevent complications. AJR Am J Roentgenol 2003;180:1399-1401.

18. Adams MT, Saltzman B, Perkins JA. Head and neck lymphatic malformation treatment: a systematic review. Otolaryngol Head Neck Surg 2012;147:627-639.

19. Roh JL. Primary treatment of ranula with intracystic injection of OK432. Laryngoscope 2006;116:169-172.

20. Lee HM, Lim HW, Kang HJ, Chae SW, Hwang SJ, Jung KY, et al. Treatment of ranula in pediatric patients with intralesional injection of OK-432. Laryngoscope 2006;116:966-969.

21. Jain $P$, Jain R, Morton RP, Ahmad Z. Plunging ranulas: highresolution ultrasound for diagnosis and surgical management. Eur Radiol 2010;20:1442-1449.

22. Kim MG, Lee NH, Ban JH, Lee KC, Jin SM, Lee SH. Sclerotherapy of branchial cleft cysts using OK-432. Otolaryngol Head Neck Surg 2009;141:329-334.

23. Roh JL, Sung MW, Hyun Kim K, II Park C. Treatment of branchial cleft cyst with intracystic injection of OK-432. Acta Otolaryngol 2006;126:510-514.

24. Fukumoto K, Kojima T, Tomonari H, Kontani K, Murai S, Tsujimoto F. Ethanol injection sclerotherapy for Baker's cyst, thyroglossal duct cyst, and branchial cleft cyst. Ann Plast Surg 1994;33:615-619.

25. Goyal N, Zacharia TT, Goldenberg D. Differentiation of branchial cleft cysts and malignant cystic adenopathy of pharyngeal origin. AJR Am J Roentgenol 2012;199:W216-W221.

26. Chow TL, Choi CY, Hui JY. Thyroglossal duct cysts in adults treated by ethanol sclerotherapy: a pilot study of a nonsurgical technique. Laryngoscope 2012;122:1262-1264.

27. Kim SM, Baek JH, Kim YS, Sung JY, Lim HK, Choi H, et al. Efficacy and safety of ethanol ablation for thyroglossal duct cysts. AJNR Am J Neuroradiol 2011;32:306-309.

28. Foley DS, Fallat ME. Thyroglossal duct and other congenital midline cervical anomalies. Semin Pediatr Surg 2006;15:70-75. 
29. Kaselas Ch, Tsikopoulos G, Chortis Ch, Kaselas B. Thyroglossal duct cyst's inflammation. When do we operate? Pediatr Surg Int 2005;21:991-993.

30. Branstetter BF, Weissman JL, Kennedy TL, Whitaker M. The CT appearance of thyroglossal duct carcinoma. AJNR Am J Neuroradiol 2000;21:1547-1550.

31. Sung JY, Baek JH, Kim KS, Lee D, Ha EJ, Lee JH. Symptomatic nonfunctioning parathyroid cysts: role of simple aspiration and ethanol ablation. Eur J Radiol 2013;82:316-320.

32. Wakabayashi K, Takahashi T, Tejima S. Parathyroid cyst. Nihon
Rinsho 1995;53:1004-1007.

33. Hamilton BE, Nesbit GM, Gross N, Andersen P, Sauer D, Harnsberger $H R$. Characteristic imaging findings in lymphoceles of the head and neck. AJR Am J Roentgenol 2011;197:1431-1435.

34. Roh JL, Park Cl. OK-432 sclerotherapy of cervical chylous lymphocele after neck dissection. Laryngoscope 2008;118:9991002.

35. Qureishi A, Silva P, Lamyman A, Cox G. Cervical lymphocoele: a simple solution for a complicated problem. Ann R Coll Surg Engl 2012;94:e79-e80. 